\title{
PREVALENCE \& CHARACTERISTICS OF MOTHERS WITH MULTIPLE PREGNANCIES AND ASSOCIATED LABOUR COMPLICATIONS AT MUHIMBILI NATIONAL HOSPITAL, SEPTEMBER 2005
}

BY SIKOSANA, MAJID. L. (MD 4-2005/2006)

\begin{abstract}
Objective: To determine the prevalence \& characteristics of mothers with multiple pregnancies and associated labour complications at Muhimbili National Hospital

Design: Retrospective Case control Study

Subjects/Materials: A hospital based retrospective study. All women who delivered (live and still births) at Muhimbili National Hospital between January 2005 and June 2005 only. The required information was obtained from the record books of the Department of Obstetrics \& Gynaecology.
\end{abstract}

Results: Revealed incidence of multiple pregnancies was 30.1 per 1000 deliveries and a significant difference between the gestational ages at delivery between multiple pregnancies and controls. The twin pregnancies approximately 3 times more likely to deliver prematurely (odd ratio $3.90\{1.08<\mathrm{OR}<15.36)$. There was no particular characteristic identified by this study that would put particular women at risk of having a multiple pregnancy.

Conclusion/recommendations: Multiple pregnancies continue to carry a high risk and women with multiple pregnancies should be offered extra care during the antenatal period with the specific objectives of early diagnosis and timely treatment of complications.

\section{Correspondence to:}

Majid L. Sikosana: +255741551127

\section{INTRODUCTION}

Multifoetal pregnancies are high-risk pregnancies with a number of associated foetal and neonatal 
complications. Multiple pregnancies often require aggressive neonatal intensive care, which is costly and stressful for the family and the infant. The foetal mortality rate for twins is 4 times the foetal mortality rate for single births. The neonatal mortality rate for twins is 6 times more than the neonatal mortality rate for single births ${ }^{1}$. Monozygotic twins are twice as likely as dizygotic twins to be born with congenital malformations. Infants born from a multiple pregnancy are at a greater risk for infant mortality and CNS pathology such as cerebral palsy and physical problems that can result from premature delivery ${ }^{5}$. Multiple pregnancies are high-risk, with most complications two to three times more likely than for a pregnancy with one baby. Nearly every part of the multiple birth experience is different. Women carrying two or more babies need more calories, higher weight gain, more rest, and more intensive prenatal care.

\section{METHODS}

The retrospective case control study was carried out at Muhimbili National Hospital. The sample size of 58 multiple pregnancies was calculated. Eligibility criteria; All women who delivered (live and still births) at Muhimbili National Hospital (MNH) from January 2005 until the sample size was obtained. Exclusion criteria; incomplete records during this time period.

The patients' records at MNH were reviewed and prepared check lists were used in order to collect important relevant information from the records.

Data obtained was entered into a computerised database and analysed using Epi-Info 2002 software package

TABLE 1

\begin{tabular}{llll}
\hline GESTATIONAL AGE & MULTIPLE PREGNANCY & CONTROL GROUP & $P$-VALUE \\
\hline $\mathbf{3 3 4}$ WEEKS & $13(22.4 \%)$ & $4(6.9 \%)$ & 0.02 \\
\hline $\mathbf{3 5}-\mathbf{3 7}$ WEEKS & $34(58.6 \%)$ & $40(69.0 \%)$ & 0.25 \\
\hline$\geq \mathbf{3 8}$ WEEKS & $11(19.0 \%)$ & $14(24.1 \%)$ & 0.46 \\
\hline TOTAL & $58(100 \%)$ & $58(100 \%)$ & \\
\hline
\end{tabular}

The mean gestational age at the time of delivery was 35.2 weeks and 36.4 weeks for the study group and the controls respectively. There was a significant difference between both groups which was statistically significant $(P<0.05$, for $\leq 34$ weeks). The twin pregnancies approximately 3 times more likely to deliver prematurely (odd ratio $3.90\{1.08<\mathrm{OR}<15.36$ )

TABLE 2
The data was taken from the month of January 2005 in order to obtain up to date current data and convince that recent data is easier to find. The control group consisted of the single pregnancies immediately registered after each multiple pregnancy case over the same period. (The controls were used for comparison against the mothers of multiple pregnancies)

Ethical issues were observed and confidentiality maintained Ethical clearance was obtained from MUCHS.

\section{RESULTS}

During the 3 month period (January 2005 - March 2005) it took to get the sample size of fifty eight (58). There were a total of 1922 deliveries at MNH, out of the fifty eight multiple births, there were fifty seven sets of twins and one set of triplets. This gives the incidence of multiple pregnancies of 30.1 per 1000 deliveries.

The age of the patients ranged from sixteen to thirty eight with a mean of $\mathbf{2 6 . 3}$ and mode of twenty three years. Age range for the control group was the same with a mean of $\mathbf{2 7 . 1}$ and a mode of $\mathbf{3 1}$ years. Four $(6.9 \%)$ of the patients had histories of previous multiple births while three $(5.2 \%)$ of patients in the control group had histories of multiple births. The parity of the study cases ranged from 0 to 6 , with a mean of 1.5 , whereas the parity for the controls ranged from 0 to 4 with a mean of 1.4 . 


\begin{tabular}{llll}
\hline DELIVERY & MUlTiPle PrEgNANCY & CONTROL GrouP & $\boldsymbol{P}$-VALUE \\
\hline SPONTANEOUS VAGINAL & $28(48.3 \%)$ & $39(67.2 \%)$ & 0.03 \\
\hline CAESAREAN SECTION & $14(24.1 \%)$ & $19(32.8 \%)$ & 0.30 \\
\hline ABD & $8(13.8 \%)$ & 0 & 0.004 \\
\hline SVD/ABD & $7(12.1 \%)$ & 0 & 0.006 \\
\hline LCVE & $1(1.7 \%)$ & 0 & 0.30 \\
\hline TOTAL & $58(100 \%)$ & $58(100 \%)$ & \\
\hline
\end{tabular}

The mode of delivery in the study cases significantly differs from the controls. The incidence of Spontaneous vaginal delivery (SVD) was $28(48.3 \%)$ in the patients and $39(67.2 \%)$ which was significantly different $\left(X^{2}\right.$ $4.28 p=0.03)$, meaning that single pregnancies are more likely to have SVD. The incidence of assisted breech delivery (ABD) was $8(13.8 \%)$ babies for the multiple pregnancies, compared with none for the controls, this difference was statistically significant $\left(\mathrm{X}^{2} 8.59, p=0.004\right)$. The incidence of $\mathrm{SVD} / \mathrm{ABD}$ was $7(12.1 \%)$ for the multiple pregnancies and none for the controls which was statistically significant $(X 2=7.45 p=0.006 I)$.

TABLE 3

\begin{tabular}{llll}
\hline Birth Weight & MUltiple Pregnancy $\left(\mathbf{1}^{\mathrm{ST}}\right.$ TWIN) & CONTROL GrouP & $P$-VALUE \\
\hline$<1500$ GRMS & $7(12.1 \%)$ & 0 & 0.006 \\
\hline $1501-2500$ GRMS & $33(56.9 \%)$ & $11(19.0 \%)$ & 0.00003 \\
\hline$>2500$ GRMS & $18(31.0 \%)$ & $47(81.0 \%)$ & 0.0000001 \\
\hline TOTAL & $58(100 \%)$ & $58(100 \%)$ & \\
\hline
\end{tabular}

The Birth weights for multiple and singleton pregnancies significantly differed, for $<1500$ gm 7 (12.1\%) of the first twins fell into this group while none of the singletons fell into his range and this was significant $(\mathrm{X}$ $7.45 p=0.006)$. For the next range of $1501-2500 \mathrm{gm} 33(56.9 \%)$ of the multiple pregnancies feel into this range while only $11(19 \%)$ of the control feel here which was significantly different with the multiple pregnancy first twin having five times the risk of being this weight compared to a singleton pregnancy $(\mathrm{X} 217.72 p=0.00003$, Odds ratio $5.64[2.27<) \mathrm{R}<14.28])$. For the $2500 \mathrm{grm}$ there were only $18(31.0 \%)$ multiple pregnancy first twins in this range while there were $47(81.0 \%)$ singletons which was also significant (X2 $29.43 p=0.0000001)$.

\section{TABLE 4}

\begin{tabular}{llll}
\hline COMPLICATIONS & MULTIPLE PREGNANCY & CONTROL GROUP & P-VALUE \\
\hline ABORTION & $1(1.7 \%)$ & 0 & 0.30 \\
\hline BIG BABY & $2(3.4 \%)$ & 0 & 0.15 \\
\hline BREECH & $4(6.9 \%)$ & $1(1.7 \%)$ & 0.17 \\
\hline DISC PROLAPSE & $1(1.7 \%)$ & 0 & 0.30 \\
\hline ECLAMPSIA & $4(6.9 \%)$ & $1(1.7 \%)$ & 0.04 \\
\hline IUFD & 0 & 0 & - \\
\hline OBSTRUCTED LABOUR & $2(3.4 \%)$ & $4(6.9 \%)$ & 0.40 \\
\hline PIH & $3(5.2 \%)$ & $1(1.7 \%)$ & 0.30 \\
\hline POST PARTUM HAEMORAGE & $2(3.4 \%)$ & 0 & 0.15 \\
\hline PREVIOUS CAESAREAN & $4(6.9 \%)$ & $5(8.6 \%)$ & 0.70 \\
\hline PROLONGED LABOUR & $1(1.7 \%)$ & 0 & 0.30 \\
\hline
\end{tabular}


In all situations, the multiple pregnancy cases showed higher frequency in all the parameters measured, except for Obstructed labour and cases of previous caesarean. There was a significant difference in the Eclampsia incidence between the multiple and singleton ( $\mathrm{X} 24.14 p=0.04)$

\section{DISCUSSION}

In the present study, the overall incidence of multiple pregnancies was 30.1 per 1000 deliveries. This is well above the intermediate range of 9 to 20 per 1000 in Europe and many African, American and Asian countries ${ }^{3}$, it falls in-between the values of two previous studies done in Tanzania, of which the south western highlands of Tanzania ranged from fifteen to twenty per 1000 deliveries, and in Kwimba district Mwanza region which had a prevalence of 39 per 1000 deliveries ${ }^{4}$. This value may not be as high above the intermediate due to the fact that Muhimbili National Hospital is the top referral hospital in the hospital, and twin pregnancies if diagnosed before labour would be sent here for delivery.

Multiple pregnancies are recognized as having an increased risk of complications during pregnancy, labour and delivery. In all situations, as in the literature ${ }^{1}$ the multiple pregnancy cases showed higher frequency in all the parameters measured, except for obstructed labour and cases of previous caesarean. The most important complication of any pregnancy is delivery before term (before 34 weeks) and in multiple pregnancies entirely almost all complications are prematurity- related ${ }^{5}$. The study confirmed this, there was a significant difference between both groups which was statistically significant with multiple pregnancy. The twin pregnancies approximately 3 times more likely to deliver prematurely (odd ratio 3.90 $1.08<\mathrm{OR}<15.36$ ). this coincides with a study done in Israel ${ }^{6}$. There was also a significant difference in the Eclampsia incidence between the multiple and singleton $\left(\chi^{2} 4.14 p=0.04\right)$, this could be due to a number of factors such as a higher amount of stress on the single placenta, making it more predisposed to damage and increasing the chances of Eclampsia, but further investigation has to be done to find the exact factors.

The mode of delivery in the study cases significantly differs from the controls which does coincide with other studies done, for example in a study done in Canada the caesarean section rate was $32.2 \%$ as compared with $3.6 \%$ for the singles pregnancy the difference again may be due to the fact that Muhimbili hospital is the top most referral hospital in the country so most of the singleton deliveries are complicated ones and tend to be solved by Caesarean section. The still births for the twins was 9.4\% (94 still birth per 1000 multiple pregnancy deliveries) compared to $3.4 \%$ (34 still births per 1000 singleton deliveries) (approximately 3 times higher) which coincides but not a high as a study done by Terence Zach et al which stated that the rate was higher.There was no particular characteristic identified by this study that would put particular women at risk of having a multiple pregnancy. This coincides with a study done by Edwards RG, et al and Alikani M, et al.

\section{CONCLUSION \& RECOMMENDATIONS}

Multiple pregnancy continues to carry a high risk and women with multiple pregnancies should be offered extra care during the antenatal period with the specific objectives of early diagnosis and timely treatment of complications, but this can only be accomplished if the women go to antenatal clinics regularly and are examined by well trained health workers and by try by all means to deliver at a facility that can cater to their greater needs such as referral hospitals, but this is difficult in the third world were resources are limited and unfortunately these are the areas with very high incidences of multiple pregnancy.

\section{REFERENCES}

1. Terence Zach, Arun Pramanik, Multiple Births

Http://www.emedicine.com/ped/topic2599.ht $\mathrm{m}$

2. Womens health channel; multiple pregnancy and fetal complications. http://www.womenshealthchannel.com/multi plepregnancies/risks babies.shtml

3. Alikani M, Noyes N, Cohen J, Rosenwaks Z. Monozygotic twinning in the human is associated with the zona pellucida architecture. Hum Reprod 1994;9:1318-21

4. van Roosmalen J.; Multiple pregnancy as a risk factor in rural Tanzania. Mbozi Designated District Hospital, Tanzania. Trop Geogr Med. 1988 Jul;40(3):196-200

5. Stuart C, Lees C (eds); Obstetrics by Ten Teachers $17^{\text {th }}$ edition chapter 13

6. Ezra Y, Shveiky D, Ophir E, Nadjari M, Eisenberg VH, Samueloff A, Rojansky; 